\title{
ORGANOGÊNESE IN VITRO DE Citrus EM FUNÇÃO DE CONCENTRAÇÕES DE BAP E SECCIONAMENTO DO EXPLANTE ${ }^{1}$
}

\author{
THAÍS LACAVA DE MOURA², WELITON ANTONIO BASTOS DE ALMEIDA ${ }^{3}$, BEATRIZ MADALENA \\ JANUZZI MENDES ${ }^{4}$, FRANCISCO DE ASSIS ALVES MOURÃO FILHO ${ }^{5}$
}

\begin{abstract}
RESUMO - O sucesso de técnicas biotecnológicas no melhoramento in vitro de Citrus depende diretamente do desenvolvimento de protocolos eficientes para regeneração de plantas. Objetivou-se avaliar o efeito de concentrações de 6-benzilaminopuria (BAP) na organogênese in vitro de limão- 'Cravo' e laranja-'Pêra', bem como o efeito do seccionamento do explante em laranja-'Valência'. Para o limão-'Cravo', foram utilizados como explante, segmentos internodais de plântulas germinadas in vitro, cultivados em meio MT e variando-se as concentrações de BAP em 0;2,5; 5; 7,5 e 10 mg.L.-1. Nas laranjas-'Pêra' e 'Valência' os explantes foram segmentos do epicótilo de plântulas germinadas in vitro. Os explantes de laranja-'Pêra' foram cultivados em meio MT variando-se as concentrações de BAP em 0; 1; 2; 3 e 4 mg.L-1. Para a laranja-'Valência', metade dos explantes foram seccionados e cultivados em meio MT acrescido de 1,0 mg.L $\mathrm{L}^{-1}$ de BAP. Todas as brotações obtidas foram alongadas no meio de cultura MT $+25 \mathrm{~g} . \mathrm{L}^{-1}$ de sacarose $+1 \mathrm{mg} . \mathrm{L}^{-1}$ de ácido giberélico $\left(\mathrm{GA}_{3}\right)$ e enraizadas no meio $\mathrm{MT}+25 \mathrm{~g} \cdot \mathrm{L}^{-1}$ de sacarose $+0,5 \mathrm{~g} \cdot \mathrm{L}^{-1}$ de carvão ativado $+1 \mathrm{mg} . \mathrm{L}^{-1}$ de ácido naftaleno acético (ANA). O melhor resultado para o número de brotações adventícias foi obtido na concentração 2,5 mg.L-1 de BAP para limão- 'Cravo', e nas concentrações 1,0 e 2,0 mg.. $\mathrm{L}^{-1}$ de BAP para laranja-'Pêra'. O seccionamento dos explantes favoreceu a organogênese in vitro da laranja-'Valência', porém as brotações apresentaram menor índice de enraizamento.
\end{abstract}

Termos para indexação: cultura de tecidos, micropropagação, benzilaminopurina

\section{CITRUS IN VITRO ORGANOGENESIS RELATED TO BAP CONCENTRATIONS AND EXPLANT SECTION}

\begin{abstract}
The establishment of efficient plant regeneration protocols is essential for the success and application of in vitro breeding biotechnologies in Citrus. The objective of this work was to verify the effect of 6-benzilaminopurine (BAP) on the in vitro organogenesis of Rangpur lime (Citrus limonia (L.) Osbeck) and 'Pera' sweet orange (Citrus sinensis (L.) Osbeck), and the effect of cutting the explant on the in vitro organogenesis of 'Valencia' sweet orange (Citrus sinensis (L.) Osbeck). For Rangpur lime, internodal explants were cultured in MT medium, with $25 \mathrm{~g} . \mathrm{L}^{-1}$ sucrose and supplemented with different concentrations of BAP $(0 ; 2.5 ; 5 ; 7.5 ; 10$ $\left.\mathrm{mg} . \mathrm{L}^{-1}\right)$. Epicotyl explants were used for 'Pera' and 'Valencia' sweet oranges. For 'Pera' sweet orange, the explants were cultured in MT medium, with $25 \mathrm{~g} . \mathrm{L}^{-1}$ sucrose and supplemented with different concentrations of BAP $\left(0 ; 1 ; 2 ; 3 ; 4 \mathrm{mg} . \mathrm{L}^{-1}\right)$. For 'Valencia' sweet orange, the epicotyl explants were cut in half and cultured on MT medium, with $25 \mathrm{~g} . \mathrm{L}^{-1}$ of sucrose and $1 \mathrm{mg} . \mathrm{L}^{-1}$ of BAP. Shoot elongation was accomplished on MT $+25 \mathrm{~g} . \mathrm{L}^{-1}$ sucrose $+1 \mathrm{mg} \cdot \mathrm{L}^{-1}$ gibberelic acid $\left(\mathrm{GA}_{3}\right)$ and rooted on MT $+25 \mathrm{~g} . \mathrm{L}^{-1}$ of sucrose $+0,5 \mathrm{~g} . \mathrm{L}^{-1}$ of activated charcoal $+1 \mathrm{mg} . \mathrm{L}^{-1} \mathrm{NAA}$. The best results for number of buds was $2.5 \mathrm{mg} . \mathrm{L}^{-1}$ of BAP in Rangpur lime and $1 \mathrm{and} 2 \mathrm{mg} . \mathrm{L}^{-1}$ in 'Pera' sweet orange. The cut of the explant in half was favorable to the in vitro organogenesis in 'Valencia' sweet orange, but it was not for rooting.
\end{abstract}

Index terms: tissue culture, micropropagation, benzylaminopurine

\section{INTRODUÇÃO}

A citricultura é uma atividade agrícola importante para o Brasil, sendo o Estado de São Paulo o maior produtor de citros, representando $83 \%$ da produção brasileira de laranja e $95 \%$ de suco para exportação. A laranja é o oitavo produto de exportação do Brasil, responsável por 2,6\% do total exportado. Em 1998, a laranja foi o primeiro produto de exportação do Estado de São Paulo e, em 1999, foi o segundo (Fundecitrus, 2000). Mesmo diante desta importância da citricultura, ainda existe a necessidade de encontrar alternativas para solucionar alguns problemas inerentes à cultura, tais como o uso predominante do limão'Cravo' como porta-enxerto, obtenção de cultivares resistentes e/ou tolerantes a determinados patógenos, bem como a obtenção de cultivares de laranja precoces, visando à industrialização.

O melhoramento genético de citros apresenta-se como uma importante alternativa em busca da solução dos problemas citados, embora ainda não tenha apresentado o resultado esperado. Segundo Cristofani (1991), as limitações do melhoramento genético convencional dos Citrus são um reflexo do comportamento genético e reprodutivo deste gênero, influenciadas por fatores tais como, longo ciclo reprodutivo,

\footnotetext{
1 Trabalho $n^{0}$ 200/2000. Recebido: 05/09/2000. Aceito para publicação: 17/03/2001. Apoio financeiro do Fundo Paulista de Defesa da Citricultura (FUNDECITRUS)

2 Acadêmica de Engenharia Agronômica. USP/ESALQ. Bolsista FUNDECITRUS

3 Prof. Depto. de Fitotecnia da AGRUFBA. Pós-Graduando do Depto. de Produção Vegetal. USP/ESALQ. Bolsista CAPES/PICDT

4 Profa. Associada. Laboratório de Biotecnologia Vegetal. USP/CENA. Bolsista CNPq

5 Prof. Associado. Depto. de Produção Vegetal. USP/ESALQ. Bolsista CNPq. Autor correspondente. famourao@esalq.usp.br
} 
apomixia, alto grau de heterozigosidade e sementes poliembriônicas.

A utilização de técnicas de cultura de tecidos constituise numa importante ferramenta de auxílio ao melhoramento genético dos citros, pois apresenta grande potencialidade e estratégias para estudos de fenômenos citológicos, morfológicos e fisiológicos. Os trabalhos de cultura de tecidos em citros tiveram grandes avanços a partir da última década, com o desenvolvimento de protocolos de micropropagação (Starrantino \& Russo, 1980), de cultura de calos (Kochba et al., 1982) e células em suspensão (Cabasson et al., 1995), de embriogênese somática (Kunitake, 1995), de organogênese (Peres-Molphe-Balch \& Ochoa-Alejo, 1997), de isolamento e cultivo de protoplastos (Grosser \& Gmitter Junior, 1990) e de obtenção de plantas transgênicas (Luth \& Moore, 1999).

A organogênese in vitro ocorre com a formação de gemas adventícias, que são assim denominadas por terem origem em locais diferentes daqueles onde se formam no curso normal de desenvolvimento da planta. Esta via de regeneração pode ser indireta ou direta, dependendo da formação ou não de calos, respectivamente. $\mathrm{O}$ sucesso para qualquer via de regeneração in vitro depende de vários fatores, onde os fitorreguladores se destacam como os principais controladores da morfogênese in vitro. Dentre as citocininas, o BAP tem sido muito eficaz para promover a multiplicação em diversas espécies e parece ser a citocinina mais adequada para a multiplicação de parte aérea e indução de gemas adventícias (Grattaplagia \& Machado, 1998). Diversos trabalhos em frutíferas corroboram com esta afirmação, como os de Peres-Molphe-Balch \& Ochoa-Alejo (1997) em citros, Almeida et al. (1998) em abacaxizeiro, Vesco \& Guerra (1999) em goiabeira, Schwartz et al. (2000) em maciera, dentre outros. Além disso, em algumas culturas, como os citros, as brotações obtidas na fase de multiplicação geralmente são pequenas e não se encontram em condições de ser individualizadas para o enraizamento. Neste caso, necessita-se de uma fase de alongamento e as giberelinas são os principais reguladores vegetais utilizados com esta finalidade (Grattaplagia \& Machado, 1998). Posteriormente, o enraizamento das brotações é fundamental para a obtenção de plantas aclimatizadas e em condições de serem transferidas para campo. Segundo Assis \& Teixeira (1998), as auxinas são as principais responsáveis pela rizogênese, sendo o ANA e AIB as mais utilizadas, principalmente em plantas lenhosas.

O objetivo deste trabalho foi conduzir experimentos visando a avaliar a resposta organogenética in vitro em função da utilização do BAP para as variedades cítricas limão-'Cravo' e laranja-'Pêra', bem como a influência do seccionamento dos explantes para a variedade laranja-'Valência'.

\section{MATERIAL E MÉTODOS}

O trabalho foi conduzido no Laboratório de Biotecnologia de Plantas Hortícolas do Departamento de Produção Vegetal da Escola Superior de Agricultura "Luiz de Queiroz” (ESALQ), da Universidade de São Paulo (USP). Foram realizados três experimentos entre as variedades limão-'Cravo' (Citrus limonia (L.) Osbeck) e laranjas-'Pêra' e 'Valência' (Citrus sinensis (L.) Osbeck). Para as três variedades, as sementes foram retiradas dos frutos e receberam a primeira lavagem para a eliminação da mucilagem. Em câmara de fluxo laminar, a desinfestação foi realizada em solução de hipoclorito de sódio (2,5\%) e água (2:1), durante 20 minutos, e incubadas em tubos de ensaio contendo $15 \mathrm{~mL}$ do meio de cultura MT (Murashige \& Tucker, 1969), acrescido de 25 g.L L $^{-1}$ de sacarose para favorecer a germinação.

\section{Experimento 1: Efeito do BAP na organogênese in vitro de limão- 'Cravo'}

Os tubos de ensaio contendo as sementes foram colocados em câmara de crescimento com fotoperíodo de $16 \mathrm{~h}$, temperatura de $27 \pm 2^{\circ} \mathrm{C}$ e intensidade luminosa de 1500 lux, durante 60 dias. Após este período, foram utilizados como explantes, segmentos internodais das plântulas germinadas. $\mathrm{O}$ cultivo dos explantes foi realizado em placa de Petri contendo 20 $\mathrm{mL}$ do meio MT, acrescido de 25 g. $\mathrm{L}^{-1}$ de sacarose e variando-se as concentrações de BAP em 0; 2,5; 5; 7,5 e 10 mg.L $\mathrm{L}^{-1}$. As placas foram mantidas em câmara de crescimento, nas mesmas condições citadas anteriormente, por 60 dias. Posteriormente, as brotações obtidas foram cultivadas em meio de alongamento (MT +25 g.L${ }^{1}$ de sacarose $+1 \mathrm{mg} . \mathrm{L}^{-1}$ de ácido giberélico-GA 3 ), durante 60 dias. Em seguida, estas brotações foram transferidas para meio de enraizamento (MT +25 g. $\mathrm{L}^{-1}$ de sacarose + 0,5 mg. $\mathrm{L}^{-1}$ de carvão ativado $+1 \mathrm{mg} . \mathrm{L}^{-1}$ de ácido naftalenoacético-ANA), durante 60 dias. O delineamento experimental foi o inteiramente casualizado, com cinco tratamentos e oito repetições, sendo cada parcela constituída por oito segmentos internodais. Os parâmetros avaliados foram o percentual de explantes responsivos e o número de brotações por explante.

\section{Experimento 2: Efeito do BAP na organogênese in vitro de laranjeira-'Pêra'}

Os tubos de ensaio contendo as sementes foram colocados no escuro durante três semanas, para favorecer o estiolamento do epicótilo, e; posteriormente, em condições de fotoperíodo de $16 \mathrm{~h}$, por uma semana. Após este período, foram utilizados como explantes, segmentos de epicótilo com aproximadamente $1 \mathrm{~cm}$ de comprimento e cultivados em placa de Petri contendo $20 \mathrm{~mL}$ do meio MT, acrescido de $25 \mathrm{~g} . \mathrm{L}^{-1}$ de sacarose e variando-se as concentrações de BAP em $0 ; 1 ; 2 ; 3$ e $4 \mathrm{mg} . \mathrm{L}^{-1}$. As placas foram mantidas em câmara de crescimento, nas mesmas condições citadas no experimento anterior, bem como o alongamento e o enraizamento das brotações. O delineamento experimental foi o inteiramente casualizado, com cinco tratamentos e cinco repetições, sendo cada parcela constituída por oito segmentos de epicótilo. Os parâmetros avaliados foram o percentual de explantes responsivos e o número de brotações por explantes.

\section{Experimento 3: Efeito do seccionamento do explante na organogênese in vitro de laranja-'Valência'.}

Os tubos de ensaio contendo as sementes foram colocados nas mesmas condições do experimento 2. Também foram utilizados segmentos de epicótilo como explantes. Neste caso, os explantes foram cultivados em placa de Petri contendo $20 \mathrm{~mL}$ do meio MT acrescido de 25 g. $\mathrm{L}^{-1}$ de sacarose e $1 \mathrm{mg} . \mathrm{L}^{-1} \mathrm{de}$ BAP. Parte destes explantes foram seccionados longitudinalmente e a face cortada foi colocada em contato com o meio de cultura. 
As condições de cultivo foram idênticas aos experimentos anteriores, bem como os meios de alongamento e enraizamento das brotações. O delineamento experimental foi o inteiramente casualizado, com dois tratamentos e dez repetições, sendo cada parcela constituída por oito explantes. O parâmetro avaliado foi o número médio de brotações por explante.

\section{RESULTADOS E DISCUSSÃO}

\section{Efeito do BAP na organogênese in vitro de limão-'Cravo'}

Verificou-se que a concentração $2,5 \mathrm{mg} . \mathrm{L}^{-1}$ de BAP foi aquela que promoveu o maior percentual de explantes responsivos (62,5\%), embora não diferindo significativamente da concentração $5 \mathrm{mg} . \mathrm{L}^{-1}$. Observou-se, ainda, que as maiores concentrações $(7,5$ e $10 \mathrm{mg} . \mathrm{L}^{-1}$ ) exerceram efeito antagônico sobre o percentual de explantes com brotações (Figura 1). Provavelmente, estes níveis exógenos de BAP, interagindo com o nível endógeno de citocinina, causaram efeito fitotóxico, suprimindo as brotações. Esses resultados foram semelhantes aos obtidos por Pasqual \& Ando (1989a), no cultivo in vitro de gemas axilares de plântulas de Poncirus trifoliata, onde elevadas concentrações de BAP promoveram redução no percentual de explantes com brotações, sendo que a concentração ótima de BAP foi de $1 \mathrm{mg} \cdot \mathrm{L}^{-1}$, que é inferior à obtida neste trabalho $\left(2,5 \mathrm{mg} . \mathrm{L}^{-1}\right)$. Isto deve-se, provavelmente, ao potencial morfogenético inerente a cada variedade.

Com relação ao número de brotações por explantes, a concentração $2,5 \mathrm{mg} . \mathrm{L}^{-1}$ também foi aquela que promoveu o maior número ( 2 brotações/explante), não diferindo significativamente da concentração $5 \mathrm{mg} . \mathrm{L}^{-1}$, com média de 1,4 brotação/explante (Tabela 1). Já Peres-Molphe-Balch \& Ochoa-Alejo (1997) obtiveram média de 3 novos brotos por segmento internodal de lima ácida 'Galego' cultivada in vitro, na concentração de 7,5 mg. $\mathrm{L}^{-1}$ de BAP. Essa concentração pode ser considerada elevada, quando se compara ao resultado deste trabalho, onde a concentração ótima estimada foi $3,71 \mathrm{mg} . \mathrm{L}^{-1}$ de BAP, a partir da qual o número médio de brotações por explante decresceu (Figura 2). Neste experimento, não se pode afirmar que o efeito do BAP foi primário, determinando a rota que seguiram as células, ou, pelo contrário, se as células estavam predeterminadas para seguir esta rota e esse regulador vegetal apenas ativou a expressão das mesmas. Todavia, verificou-se a importância dessa citocinina na organogênese in vitro do limão-'Cravo', como se evidencia na Figura 3 . Vale ressaltar que as brotações alongaram satisfatoriamente e atingiram índice de $80 \%$ de enraizamento. Grosser \& Gmitter Júnior (1990) também obtiveram alongamento satisfatório em plântulas de híbridos somáticos de citros, utilizando $1 \mathrm{mg} . \mathrm{L}^{-1}$ de $\mathrm{GA}_{3}$ no meio de cultura. Já com relação ao enraizamento, a utilização do ANA, em concentrações variando de 0,5 a $5 \mathrm{mg} . \mathrm{L}^{-1}$, também foi fundamental para enraizar brotos de laranja-doce 'Pineapple', com índice de 85\% (Duran-Vila et al., 1989); de lima ácida 'Galego', com 70\% (Peres-Molhe-Balch \& Ochoa-Alejo, 1997) e citrange 'Troyer', com 86\% (Moreira-Dias et al., 2000).

\section{Efeito do BAP na organogênese in vitro de laranja-'Pêra'}

Os resultados apresentados na Figura 4 demonstraram que as concentrações $0 ; 1$ e 2 mg. $\mathrm{L}^{-1}$ de BAP proporcionaram 95;
85 e $65 \%$ de explantes responsivos, respectivamente, não diferindo significativamente entre si. Observou-se que, na ausência de BAP, houve o maior percentual de explantes com brotações. Este resultado indica que, provavelmente, o nível endógeno de citocinina foi suficiente para assegurar esta resposta, em virtude de o explante utilizado (segmento de epicótilo) ser oriundo de plântulas germinadas in vitro, que apresentavam sistema radicular já formado e, segundo Burch \& McGaw (1993), os meristemas das raízes são os principais responsáveis pela síntese de citocinina. Já as concentrações $3 \mathrm{e}$ $4 \mathrm{mg} . \mathrm{L}^{-1}$ de BAP conduziram à redução do percentual de explantes responsivos. Diversos trabalhos como os de Peres-MolpheBalch \& Ochoa-Alejo (1997), em lima ácida 'Galego', Otoni \& Teixeira (1991) em laranja-'Pêra' e Pasqual \& Ando (1989b) em laranja-'Valência', têm demonstrado que elevadas concentrações de BAP apresentam efeito inibitório no percentual de explantes responsivos.

Quanto ao número médio de brotações por explante, verificou-se que as concentrações 1 e $2 \mathrm{mg} . \mathrm{L}^{-1}$ foram aquelas que apresentaram o melhor resultado, com 2,53 e 2,62, respectivamente, não diferindo significativamente entre si (Tabela 2). A concentração ótima estimada neste experimento foi 0,95 mg.L $L^{-1}$ de BAP, a partir da qual houve decréscimo para o número de brotos/explante (Figura 5). Já Otoni \& Teixeira (1991), no cultivo in vitro da laranja-'Pêra', conseguiram melhor resultado na concentração de $0,75 \mathrm{mg} . \mathrm{L}^{-1}$ de BAP, com média de 3,5 brotações. Entretanto, estes autores utilizaram segmentos nodais de plantas juvenis como explante, o que pode explicar essa diferença de resposta. As brotações obtidas neste experimento também alongaram de forma satisfatória e atingiram índice de $75 \%$ de enraizamento. Ghorbel et al. (1998), utilizando ANA a $3 \mathrm{mg} . \mathrm{L}^{-1}$ no meio de enraizamento, conseguiram índice de $84 \%$ para brotos de Citrus macrophylla; no entanto, não obtiveram enraizamento para os brotos de Citrus paradisi e Citrus aurantium, concluindo que a rizogênese é genótipo-dependente.

\section{Efeito do seccionamento do explante na organogênese in vitro de Laranja-'Valência'}

Os resultados demonstraram que houve diferença significativa entre os tratamentos, onde os explantes seccionados proporcionaram média de 2,94 brotações e aqueles não seccionados apresentaram média de 1,6 brotação (Figura 6). Segundo Cutter (1986), o seccionamento em regiões próximas a meristemas e parênquimas estimula a divisão celular. Assim, é provável que o seccionamento realizado neste trabalho, combinado com a aplicação exógena de citocinina (BAP), tenha estimulado maior divisão celular e, conseqüentemente, maior diferenciação de gemas adventícias, conduzindo ao maior número de brotações, quando comparado com os explantes não seccionados. Entretanto, as brotações oriundas dos explantes seccionados apresentaram-se pouco desenvolvidas, provavelmente devido à maior competição nutricional no meio de cultura e à menor reserva endógena do explante seccionado. Este fato, possivelmente, contribuiu para o alongamento insatisfatório das brotações e índice de enraizamento de apenas $45 \%$, enquanto naquelas oriundas dos explantes não seccionados, este índice alcançou $80 \%$. 
TABELA 1 - Efeito das concentrações de BAP, sobre o número de brotações por explante de limão- 'Cravo'

\begin{tabular}{cc}
\hline $\begin{array}{c}\text { Concentração de B A P } \\
\left(\mathbf{m g . L}^{-1}\right)\end{array}$ & Número médio de brotações por explante* \\
\hline 0,0 & $0,6 \mathrm{bc}$ \\
2,5 & $2,0 \mathrm{a}$ \\
5,0 & $1,4 \mathrm{ab}$ \\
7,5 & $0,2 \mathrm{c}$ \\
10,0 & $0,3 \mathrm{bc}$ \\
\hline
\end{tabular}

*Médias seguidas da mesma letra não diferem entre si pelo teste de Tukey-5\%

TABELA 2 - Efeito das concentrações de BAP, sobre o número de brotações por explante de laranja-'Pêra'.

\begin{tabular}{cc}
\hline $\begin{array}{c}\text { Concentração de BAP } \\
\left(\mathbf{m g . L}^{-1}\right)\end{array}$ & Número médio de brotações por explante* \\
\hline 0,0 & $1,32 \mathrm{~b}$ \\
1,0 & $2,53 \mathrm{a}$ \\
2,0 & $2,62 \mathrm{a}$ \\
3,0 & $1,62 \mathrm{~b}$ \\
4,0 & $1,67 \mathrm{~b}$ \\
\hline
\end{tabular}

*Médias seguidas da mesma letra não diferem entre si pelo teste de Tukey-5\%

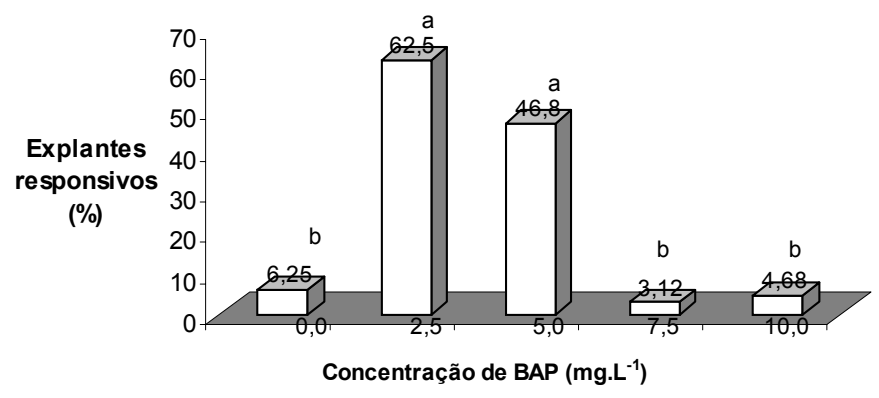

FIGURA 1 - Percentual de explantes responsivos de limão- 'Cravo' em função das concentrações de BAP. PiracicabaSP, 2000. Barras seguidas da mesma letra não diferem significativamente pelo teste de Tukey-5\%.

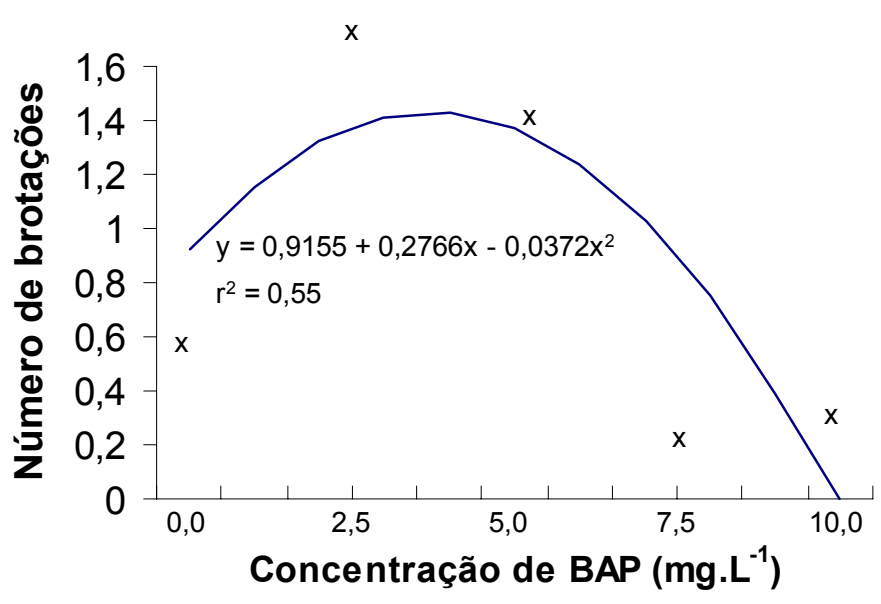

FIGURA 2 - Número médio de brotações por explante de limão'Cravo' em função das concentrações de BAP. Piracicaba-SP, 2000.
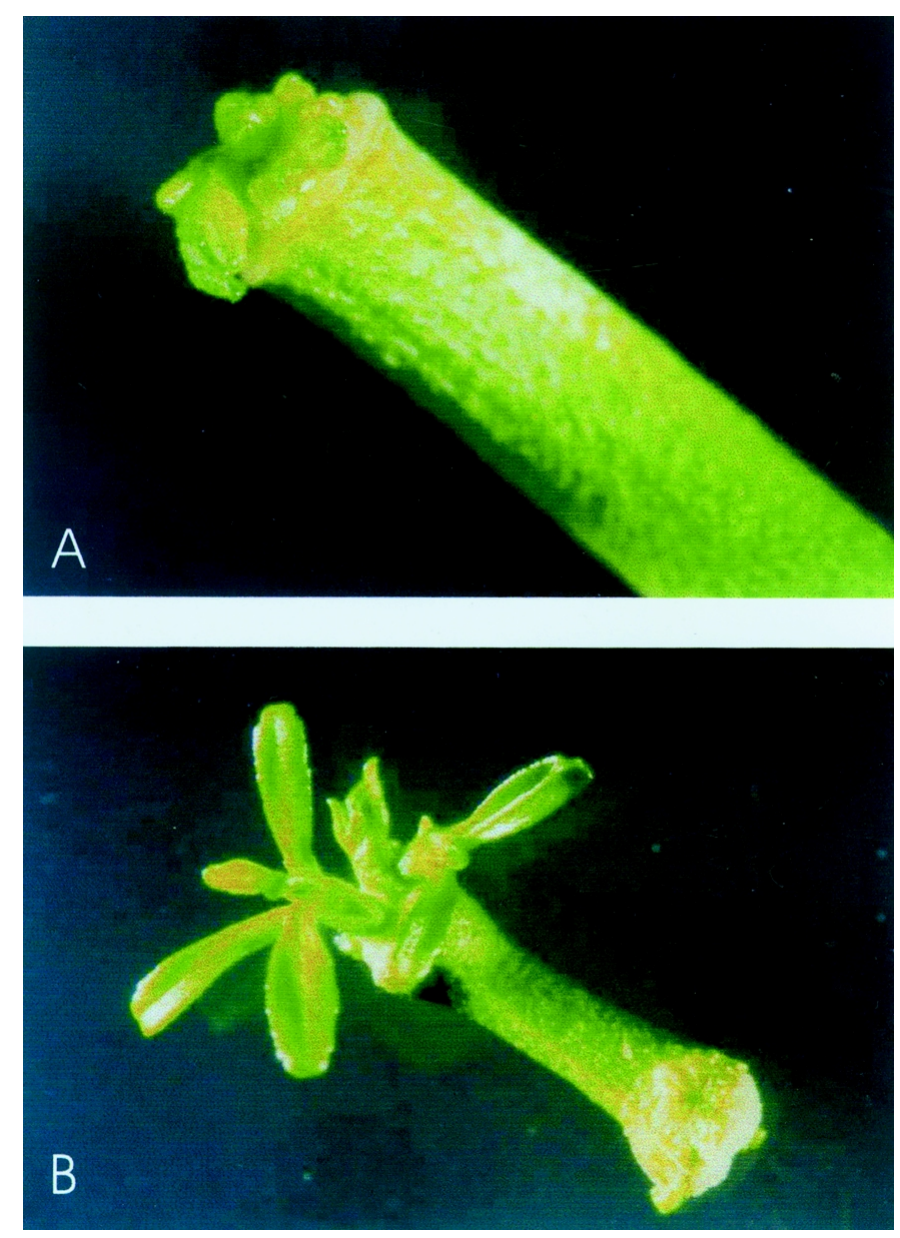

FIGURA 3 - Formação de gemas adventícias em segmento internodal de limão- 'Cravo' na concentração 2,5 mg.L.-1 de BAP. A. início de formação de gemas; B. desenvolvimento de gemas adventícias. 


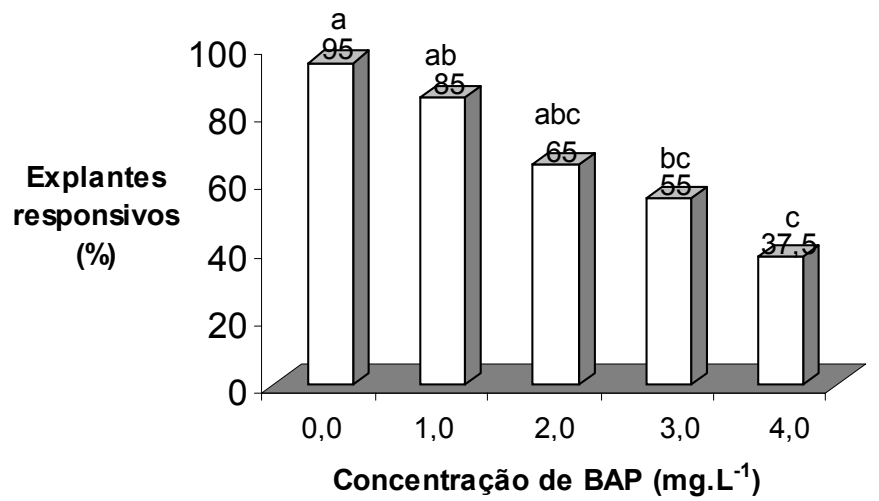

FIGURA 4 - Percentual de explante responsivos da laranja-'Pêra' em função das concentrações de BAP. PiracicabaSP, 2000. Barras seguidas da mesma letra não diferem entre si pelo teste de Tukey-5\%.

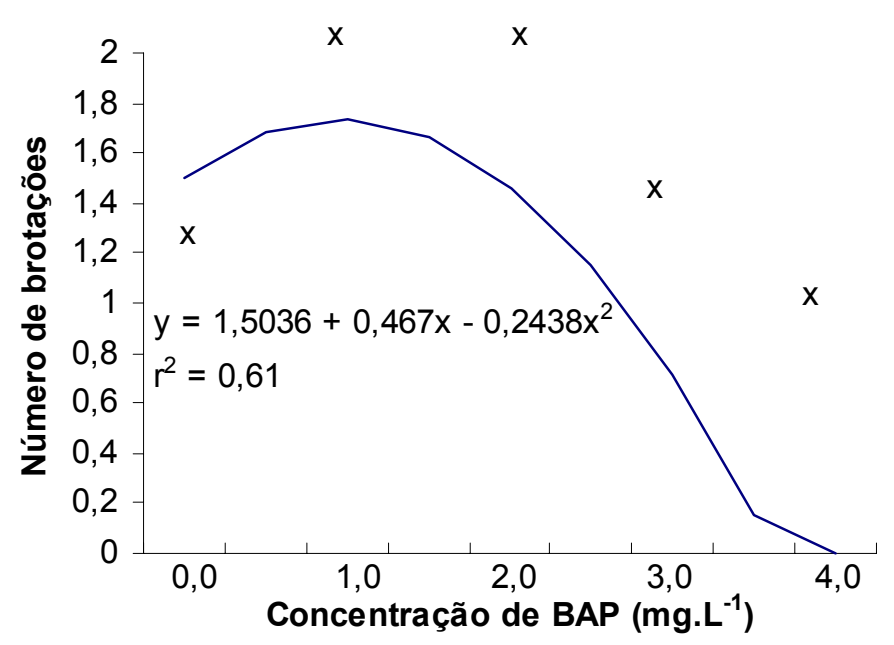

FIGURA 5 - Número médio de brotações por explante da laranja'Pêra' em função das concentrações de BAP. Piracicaba-SP, 2000.

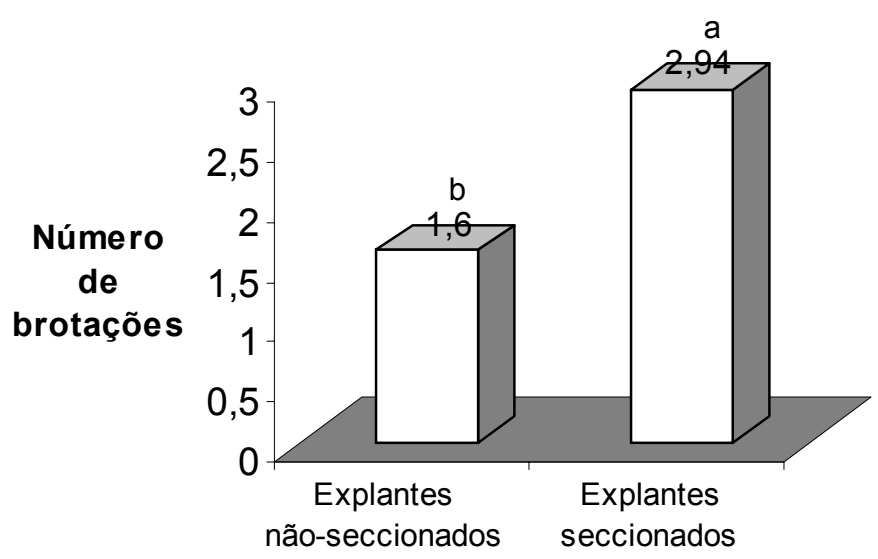

FIGURA 6 - Número médio de brotações por explante da laranja-

'Valência' em função do seccionamento dos explantes. Piracicaba-SP, 2000. Barras seguidas de letras distintas diferem entre si pelo teste de Tukey$5 \%$.

\section{CONCLUSÕES}

De acordo com experimentos realizados neste trabalho, pode-se concluir que:

1 - A concentração 2,5 mg. $\mathrm{L}^{-1}$ de BAP foi aquela que melhor favoreceu a organogênese in vitro em segmentos internodais de limão- ‘Cravo', tanto para o percentual de explantes responsivos, como para o número de brotações adventícias.

2 - A concentração 1 e 2 mg. $L^{-1}$ de BAP foram aquelas que melhor favoreceram a organogênese in vitro em segmentos de epicótilo da laranja-'Pêra', principalmente para o número de brotações adventícias.

3 - O alongamento das brotações nas variedades limão- 'Cravo' e laranja-'Pêra' foi satisfatório, e as mesmas atingiram $80 \%$ e $75 \%$ de enraizamento, respectivamente.

4 - O seccionamento dos segmentos de epicótilo favoreceu a organogênese in vitro da laranja-'Valência', quando comparado com aqueles não-seccionados, porém as brotações adventícias obtidas apresentaram alongamento insatisfatório e menor índice de enraizamento.

\section{REFERÊNCIAS BIBLIOGRÁFICAS}

ALMEIDA, W. A. B. de; MATOS, A. P. de; SOUZA, A. de S. Influência da benzilaminopurina (BAP) no desenvolvimento de plântulas do abacaxizeiro (Ananas comosus (L.) Merr.) cultivadas in vitro. Magistra, n. 10, p. 55-63, 1998.

ASSIS, T. F. de; TEIXEIRA, S. L. Enraizamento de plantas lenhosas. In: TORRES, A. C.; CALDAS, L. S.; BUSO, J. A. Cultura de tecidos e transformação genética de plantas. EmbrapaSPI, v. 1, 1998. p. 261-296.

BURCH, L. R.; McGAW, B. A. Citoquininas. In: BIETO, J. A.; TALON, M. Fisiologia y bioquimica vegetal. Espanha: Ed. Interamericana, 1993.625p.

CABASSON, C.; OLLITRAULT, P.; CÔTE, F-X.; FERRIERE, NM.;DAMBIER, D.;DALNIC, R.; TEISSON, C. Characteristics of Citrus cell cultures during undifferentiated growth on sucrose and somatic embryogenesis on galactose. Physiologia Plantarum, Copenhagen, v. 93, p. 464-470, 1995.

CUTTER, E. G. Anatomia Vegetal: células e tecidos. São Paulo: Roca, 1986.304p.

CRISTOFANI, M. Adaptação de metodologias de cultura de tecidos visando ao melhoramento através de mutações em Citrus sinensis (L.) Osbeck cv. Pêra. 1991. 185f. Dissertação (Mestrado). Escola Superior de Agricultura “Luiz de Queiroz”, Universidade de São Paulo, Piracicaba, 1991.

DURAN-VILA, N.; ORTEGA, N.; NAVARRO, L. Morphogenesis and tissue culture of three citrus species. Plant Cell, Tissue and Organ Culture, Dordrecht, v. 16, p.123-133, 1989.

FUNDECITRUS. http://www.fundecitrus.com.br (Junho 2000) GHORBEL, B. R.; NAVARRO, L.; DURAN-VILA, N. 
Morphogenesis and regeneration of whole plants of grapefruit (Citrus paradisi), sour orange (C. aurantium) and alemow ( $C$. macrophylla). Journal of Horticultural Science \& Biotecnologia, v. 73, p. 323-327, 1998.

GRATTAPAGLIA, D.; MACHADO, M. A. Micropropagação. In: TORRES, A. C.; CALDAS, L. S.; BUSO, J. A. Cultura de tecidos e transformação genética de plantas. Embrapa-SPI, 1998. v. 1, p. $184-250$

GROSSER, J. W.; GMITTER JÚNIOR, F. G. Protoplast fusion and citrus improvement. Plant Breeding Reviews, Riyadh, v. 8, p. 339-374, 1990.

KOCHBA, J.; SPIEGEL-ROY, P.; EUMANN, H.; SAAD, S. Effect of carbohydrates on somatic embryogenesis in subcultured nucelar callus of Citrus cultivars. Zeitshrift fuer Pflanzenphysiologie, Kazamizara, v. 105, p. 359-368, 1982.

KUNITAKE, H. Somatic Embryogenesis in Citrus species. In: BAJAJ, Y. P. S. (Ed.) Somatic embryogenesis and synthetic seed I. Berlin: Springer-Verlag, 1995. p. 280-298. (Biotechnology in Agriculture and Forestry, 30).

LUTH, D.; MOORE, G. Trangenic grapefruit plants obtained by Agrobacterium tumefaciens-mediated transformation. Plant Cell, Tissue and Organ Culture, Doichecht, v. 57, p.219-222, 1999.

MOREIRA-DIAS, J. M.; MOLINA, R. V.; BORDÓN, Y.; GUARDIOLA, J. L.; GARCÍA-LUIS, A. Direct and indirect shoot organogenic pathways in epicotyl cuttings of Trayer citrange differ in hormone requirements and their response to light. Annals of Botany, London, v. 85, p. 103-110, 2000.

MURASHIGE, T.; TUCKER, D. P. H. Grow factor requeriment of
Citrus tissue culture. Proceedings of the First International Citrus Simposium, v. 3, p. 1155-1669, 1969.

OTONI, W. C.; TEIXEIRA, S. L. Propagação clonal in vitro de Citrus sinensis cv. 'Pêra', a partir de segmentos nodais juvenis: I. Influência de citocininas. Revista Ceres, Viçosa, v. 38, n. 215, 1991.

PASQUAL, M.; ANDO, A. Micropropragação de 'Trifoliata' através da cultura de gemas axilares in vitro. Pesquisa Agropecuária Brasileira., Brasília, v. 24, n. 2, p. 217-220, 1989a.

PASQUAL, M.; ANDO, A. Micropropragação de laranja'Valência' através da cultura de gemas axilares in vitro. Pesquisa Agropecuária Brasileira, Brasília, v. 24, n. 6, p. 723-726, 1989 b. PERES-MOLPHE-BALCH, E.; OCHOA-ALEJO, N.. In vitro plant regeneration of Mexican lime and Mandarim by direct organogenesis. HortScience, Alexandria, v. 32, n. 5, p. 931-934, 1997.

SCHWARTZ, E.; RONCATTO, G.; FORTES, R. de L. Multiplicação in vitro do porta-enxerto de macieira cv. Marabukaido utilizando 6-benzilaminopurina e ácido naftalenoacético. Revista Brasileira de Fruticultura, Cruz das Almas, v. 22, n. 1, p. 77-79, 2000.

STARRANTINO, A.; RUSSO, F. Seedlings from undevelopment ovules of ripe fruits of polyembryonic citrus cultivars. HortScience, Alexandria, v. 15, n. 3, p. 269-267, 1980.

VESCO, L. D.; GUERRA, M. P. Organogênese e micropropagação da goiabeira serrana (Feijoa sellowiana Berg) - Lírio. Revista Brasileira de Fruticultura, Cruz das Almas, v. 21, n. 1, p. 60-64, 1999. 